\title{
Genotoxic Effect of Automobile Exhaust Exposure among Motorized Tricycle Drivers in Tuguegarao City, Cagayan, Philippines using Micronucleus Assay: A Retrospective Cohort Study
}

\author{
John Vincent A. Pagaddu, M.D.*, Marilyn Martinez, M.D., Elenita Rose Ruiz, M.D., Harold \\ Briosos, M.D., Roselyn Baculi, M.D., Lloyd Alias, M.D., Jameela Lourdes Dela Cruz, M.D., \\ Regimar Benito, M.D.
}

School of Medicine, St. Paul University Philippines, Philippines

*Corresponding Author: dospagaddu@gmail.com

Received: 01 Nov 2020; Received in revised form: 21 Jan 2021; Accepted: 15 Feb 2021; Available online: 23 Feb 2021 (C)2021 The Author(s). Published by Infogain Publication. This is an open access article under the CC BY license (https://creativecommons.org/licenses/by/4.0/).

\begin{abstract}
Motorized tricycle drivers are among the populations of the transport industry who are very much prone to the effects of hazardous substances found in automobile exhausts. This research was aimed to determine the risk factors of cytogenetic damage brought about by automobile exhaust exposure among motorized tricycle drivers of Tuguegarao City. In this study, a total enumeration of motorized tricycle drivers from of Pengue Ruyu, Tuguegarao City was done. Out of 52 tricycle drivers, only 51 participants were included in the study. Most of the tricycle drivers of Pengue Ruyu were primarily middle-aged drivers; substantially exposed to automobile exhaust; cigarette smokers and alcoholic drinkers; non-users of protective masks; had no vitamin supplementation; and had routes that involved driving across Barangay Tanza. A high incidence of genotoxicity [76.47\% (95\% CI: $64.83 \%$ to $88.11 \%$ )] among the study participants was observed. Among the categorical variables, only automobile exhaust exposure and vitamin supplementation showed significant correlation $(p<0.05)$ with the development of cytogenetic damage. Automobile exhaust exposure was found to be a risk factor, while intake of vitamins as a protective factor. Statistical analysis showed that tricycle drivers substantially exposed to combustion products in automobile exhaust had a significantly $(p<0.05)$ higher mean frequency of micronuclei and were 2.13 (90\% CI: 1.12 to 4.08) times more likely to develop cytogenetic damage than those tricycle drivers who have low confidence of exhaust exposure. Tricycle drivers who have vitamin supplementation tend to have a significantly $(p<0.05)$ lower mean frequency of micronuclei and reduce their risk of developing cytogenetic damage by $44 \%$ (90\% CI: 4\% to 55\%) than those who do not take any vitamins at all. Wearing protective masks could be a protective factor as it may reduce the risk of developing cytogenetic damage by $46 \%$ (90\% CI: $-46 \%$ to $72 \%$ ) but was found to be statistically insignificant. Identifying factors that contribute to the pathogenesis of genotoxicity in vulnerable and susceptible groups can help to plan for effective prevention strategies.
\end{abstract}

Keywords-Genotoxicity, Automobile Exhaust Exposure, Micronucleus Assay

\section{INTRODUCTION}

All life on earth needs to have a clean air to breathe. This is so because when the air becomes unhealthy, a plethora of complications may arise and may affect not only the ecological wealth of the country but most especially the health of its people (WHO, 2008) 
Based on the four-year national total suspended particulate (TSP) monitoring from 2003-2007, the Philippines pollution level has improved from $144 \mathrm{ug} / \mathrm{Ncum}$ in 2003 to 97ug/Ncum in 2007 (DENR EMB, 2009). Though there has been a stabilizing trend observed in the air quality status of the Philippines, the value still exceeded the standards set by the World Health Organization, which is at 90ug/Ncum (DENR EMB, 2009). The degradation of air quality of the Philippines could be attributed to three sources (DENR EMB, 2009). These pollution sources are stationary, mobile and area sources. Among these sources, large proportion is pointed to mobile sources $(65 \%$ of all pollution sources), as indicated in the National Emission Inventory in 2006. According to DENR EMB (2009), majority of the regions in the country attributed the degrading air quality to the transport sector, which is reported as the major source of air pollution in the Philippines.

Moreover, air pollution levels are tightly linked to climate and topography. Air pollution episodes can be particularly troublesome if the affected city is located in a valley surrounded by mountains, wherein a nocturnal inversion layer traps dangerous concentrations of pollutants in the cool air at the base of the valley that sometimes results to dense smog over urban areas (WHO, 2008). This can be observed in Tuguegarao City, which has been dubbed as the Tricycle City of Cagayan Valley Region (Domingo, 2013).

At least 12, 000 tricycles wander around Tuguegarao City (Domingo, 2013). The increasing numbers of Tricycles make Tuguegarao City one of the most polluted cities in terms of air quality. In fact, the air pollution level in Tuguegarao city has exceeded the air quality standards set by the WHO. Based on the National Air Quality Status Report (2003-2004) of DENR-EMB (2005), air pollution level of Barangay Tanza, Tuguegarao City has reached 198 ug/Ncum in 2004 from only 59 ug/Ncum in 2003. In fact, the maximum TSP level reached by Barangay Tanza in 2004 was 346 ug/Ncum (DENR-EMB, 2005).

Motorized Tricycle drivers, because of their work, are exposed to complex mixture of hazardous substances coming from automobile exhaust. The majority of situations involve exposures to low dose for a long period of time. This may involve the individual's entire lifetime and result in small increments in health risks (Franco et al., 2008). One way of studying the effects of automobile exhaust exposure on a population, especially the tricycle drivers, is to conduct a monitoring study by which damages to the DNA or to the chromosome can be identified (Pant and Rao, 2010).
Occupational exposure to hazardous substances puts a great public health concern. This is such since low doses of carcinogenic substances and mixtures, to which workers are exposed, can produce genotoxic effects (Maluf and Erdtmann, 2000). Genotoxic effects, in the form of cytogenetic damage, may be manifested by the presence of Micronuclei (MN), which are fragments or whole chromosomes that did not reach spindle poles during mitosis and remained encapsulated at telophase in a separate nucleus (Fenech et al., 2003). Micronucleus assay for exfoliated buccal mucosal cells have been used to evaluate cytogenetic damage (Maluf and Erdtmann, 2000). Several studies using Micronucleus assay have shown that smoking, alcohol, ionizing radiation, duration of exposure, and some drugs have an additive effect on the induction of cytogenetic damage.

Therefore, to add further knowledge to the genetic risk related to automobile exhaust exposure, this study will use Micronucleus (MN) as a biomarker in occupationally exposed motorized tricycle drivers. With this, the present researchers have come out with the research purpose, which is threefold: a.) to determine the risk factors of the genotoxic effects of automobile exhaust among motorized tricycle drivers of Tuguegarao City, b.) to examine relationships between the profile of the subjects and the cytogenetic damage brought about by automobile exhaust exposure using Micronucleus Assay, and c.) to determine the extent of genotoxicity among tricycle drivers.

\section{METHODOLOGY}

The research design used in this study was a retrospective cohort study design. This study examined exposure to suspected risk factors in relation to genotoxicity. In this study, a total enumeration of the Motorized Tricycle drivers of Pengue Ruyu, Tuguegarao City was done. Only those who satisfied the inclusion criteria were included in the study. The total number of tricycle drivers of Pengue Ruyu was 52. However, only 51 participants were included in the study because one of the tricycle drivers did not satisfy the inclusion criteria. The subjects were conveniently grouped based on a questionnaire that includes items about age, occupational exposure, smoking habit, consumption of alcohol, and use of protective masks, as well as the presence of micronuclei in the exfoliated buccal mucosa. The health and occupational histories of the subjects were also collected. All study participants were consented and were informed about the objective of the study. Inclusion criteria include: 1. A tricycle driver of Pengue Ruyu, Tuguegarao City, 2. Male,

3. Drives across Barangay Tanza, 4. Drives a motorized tricycle at least thrice a week, 5. Has not been exposed to 
x-rays seven days before the sampling, 6. Has not taken any antibiotics for three months prior the sampling, 7. Has not recently taken a vaccination, and 8 . No viral illnesses.

The main instruments that the researchers used in this study were modified structured questionnaires, historytaking, and microscopy. The questionnaires used in this study comprised important variables as indicated in the protocol set by Thomas et al (2009). The questions were written in a closed-ended manner and were relatively narrow. For the Micronucleus assay, a light compound microscope was used.

Health education was first executed. Informed consent was obtained prior to the conduct of interview and specimen collection. Interview of the study participants was then done. After all the necessary preliminaries, the Buccal Micronucleus assay was performed according to the protocol of Thomas et al (2009) with slight modifications.

Before buccal cell collection, the study participants were asked to rinse their mouth twice thoroughly with $100 \mathrm{ml}$ of water to remove unwanted debris. For each specimen, a $30-\mathrm{ml}$ container containing $10 \mathrm{ml}$ of Carnoy's fixative was prepared. Gently but firmly, a wooden spatula was swabbed 10 times against the inside of the cheek wall from the middle and gradually increasing in span. The spatula was then placed into the fixative container.

Buccal cells from the fixing solution were harvested for slide preparation. Samples were centrifuged for $10 \mathrm{~min}$ at $3200 \mathrm{rpm}$ at room temperature. The pellet was resuspended on $300 \mu$ l Carnoy's solution. The resulting solution was subjected to vortex mixer to increase the number of single cells in suspension. In duplicate, $100 \mu \mathrm{l}$ of cell suspension was placed onto a clean, dry and appropriately labeled microscope slide using a micropipettor. Cells were heat-fixed and were subjected to the following schedule: $2 \mathrm{~min}$ in $95 \%$ ethanol; $2 \mathrm{~min}$ in $75 \%$ ethanol; 2 min in $50 \%$ ethanol; and 2 min in distilled water.

Finally, cells were stained using Giemsa's stain. Using light microscope, the number of micronuclei in at least 1,000 differentiated cells were determined. A minimum of 1,000 cells possessing intact nuclei and cell boundaries were counted in each slide. The following criteria given by Tolbert et al. (1991) were considered to designate an extranuclear body as micronucleus: Rounded smooth perimeter suggestive of a membrane; Less than a third the diameter of the associated nucleus, but large enough to discern shape and color; Staining intensity similar to that of the nucleus; Texture similar to that of nucleus; Same focal plane as nucleus; and Absence of overlap with, or bridge to, the nucleus.
The number of micronuclei scored per slide was recorded. To ensure the certainty of MN scored per slide, an Interrater reliability technique was used.

The statistical analysis of the data obtained was done through Microsoft Excel. The mean values and standard deviation were computed for the age and MN scores. To detect a significant trend and association between variables, Fisher's exact test was performed. To establish a significant difference in the mean values between variables, Student's t-test for independent means was used. Also, to establish a significant difference between the proportions of those who have low confidence and substantial exhaust exposure, z-test for independent proportion was used. A p-value of less than 0.05 was considered significant. To determine the relative risks, risk ratios were computed. The confidence interval of each risk ratio was set at $90 \%$.

\section{RESULTS AND DISCUSSION}

\subsection{Profile of the Study Participants}

The profile of the respondents consists of three factors that are necessary in the study: (1) Personal Factor, (2) Lifestyle Factors, and (3) Occupational Factors. The personal factor consists of the respondents' age only. The lifestyle factors consist of the respondents' smoking history, alcohol consumption history, and medical history. Lastly, the occupational factors consist of the respondents' number of years in service as a tricycle driver, regularity of driving across Tanza, duration of work, as well as use of protective masks.

A total of 52 tricycle drivers of Pengue Ruyu were asked to participate in the study. However, one of the tricycle drivers, who is a female, was excluded for not satisfying the inclusion criteria set by the researchers.

Majority (80\%) of the respondents had substantial exposure to automobile exhaust, while only $20 \%$ had low confidence of exposure. This suggests that more tricycle drivers of Pengue Ruyu were exposed to automobile exhaust and were prone to having genotoxic effects.

Table 1. The Mean Age of the Tricycle Drivers of Pengue Ruyu, Tuguegarao City $(N=51)$.

\begin{tabular}{|c|c|c|c|}
\hline & N & $\begin{array}{c}\text { Mean } \\
\text { Age }\end{array}$ & $\begin{array}{c}\text { Standard } \\
\text { deviation }\end{array}$ \\
\hline Sample Population & $\mathbf{5 1}$ & $\mathbf{4 4 . 3 7}$ & $\mathbf{1 1 . 9 5}$ \\
\hline $\begin{array}{c}\text { Low Confidence of } \\
\text { Exposure }\end{array}$ & $\mathbf{1 0}$ & $\mathbf{3 8 . 6 3}$ & $\mathbf{1 3 . 2 2}$ \\
\hline Substantial Exposure & 41 & $\mathbf{4 6 . 3 2}$ & $\mathbf{1 0 . 9 6}$ \\
\hline
\end{tabular}


The mean age of the tricycle drivers of Pengue Ruyu is illustrated in Table 1. The arithmetic mean age of the sample population $(\mathrm{N}=51)$ is 44.37 years old. Meanwhile, the mean age of tricycle drivers with low confidence of automobile exhaust exposure is 38.63 years old, while the mean age of tricycle drivers with substantial exposure is 46.32 years old. The result implies that the tricycle drivers of Pengue Ruyu who had low confidence of exposure were relatively younger than the tricycle drivers with substantial exposure as well as the sample population in general. Nevertheless, the tricycle drivers of Pengue Ruyu who had substantial exposure to automobile exhaust were relatively older than the sample population.

Majority of the respondents $(67 \%)$ were smokers, while only $33 \%$ were non-smokers. Thus, more tricycle drivers of Pengue Ruyu were exposed to cigarette smoke and, as such, were prone to have genotoxic effects.

Eighty four percent of the respondents were alcoholic beverage consumers, while only $16 \%$ were alcoholic beverage abstinents. This proportion implies further that more tricycle drivers of Pengue Ruyu were exposed to noxious substances of alcoholic beverages and hence were prone to having genotoxic effects.

In this study, only a small proportion (18\%) of the sample population had a positive history of respiratory diseases (such as asthma, chronic cough, and pneumonia), while $82 \%$ denied any history of respiratory diseases.

It was observed that only $31 \%$ of the study participants had a habit of taking vitamins. A relatively lower proportion of tricycle drivers of Pengue Ruyu had a habit of taking vitamins, which may serve as antioxidants and offer protection from further occurrence of genotoxicity.

Thirty five percent of the respondents had been in the transport industry as tricycle drivers for more than 15 years, while $25 \%$ of the respondents had been driving tricycles for about 11 to 15 years. On the other hand, 20\% and $18 \%$ of the respondents had been in the transport service for about 1 to 5 years and 6 to 10 years, respectively. This just shows that more tricycle drivers of Pengue Ruyu had been exposed to automobile exhaust for a long time already, which posed a higher health risk to the tricycle drivers.

Most of the respondents $(69 \%)$ had a duration of driving around the city of about 11 to 15 hours. On the other hand, only $31 \%$ of the respondents claimed a duration of driving of 6 to 10 hours.

Also, most of the tricycle drivers of Pengue Ruyu, Tuguegarao City had consistently and substantially been exposed to automobile exhaust. As such, most of the tricycle drivers were more likely at risk of the genotoxic effects of automobile exhaust.

In the National Air Quality Status Report of DENR-EMB (2005), Barangay Tanza has reached an air pollution level of $198 \mathrm{ug} / \mathrm{Ncum}$ in 2004, which is far higher than the standards of $90 \mathrm{ug} / \mathrm{Ncum}$ by the WHO. As such, the higher frequency of driving across Barangay Tanza indeed posed a higher chance of exposure to complex mixture of hazardous substances coming from automobile exhaust. Majority of the study participants $(65 \%)$ "always" drive across Barangay Tanza, while only $35 \%$ claimed that they "sometimes" drive across Barangay Tanza.

In this study, a very small proportion $(8 \%)$ of the sample population used protective mask while driving. This means that a high proportion of tricycle drivers were very much exposed to automobile exhaust and were prone to having genotoxic effects.

Based on the profile of the study participants, most of the motorized tricycle drivers of Pengue Ruyu, Tuguegarao City were middle-aged, were substantially exposed to automobile exhaust, were cigarette smokers, were alcoholic drinkers, were non-users of protective masks, had no history of any respiratory diseases, had no habit of taking vitamins, and always drive across Tanza.

\subsection{Extent of the Genotoxicity of Automobile Exhaust}

The photomicrograph of micronucleated buccal cells collected from the sample was shown in Fig. 1. The presence of micronuclei in buccal cells indicates a positive result.

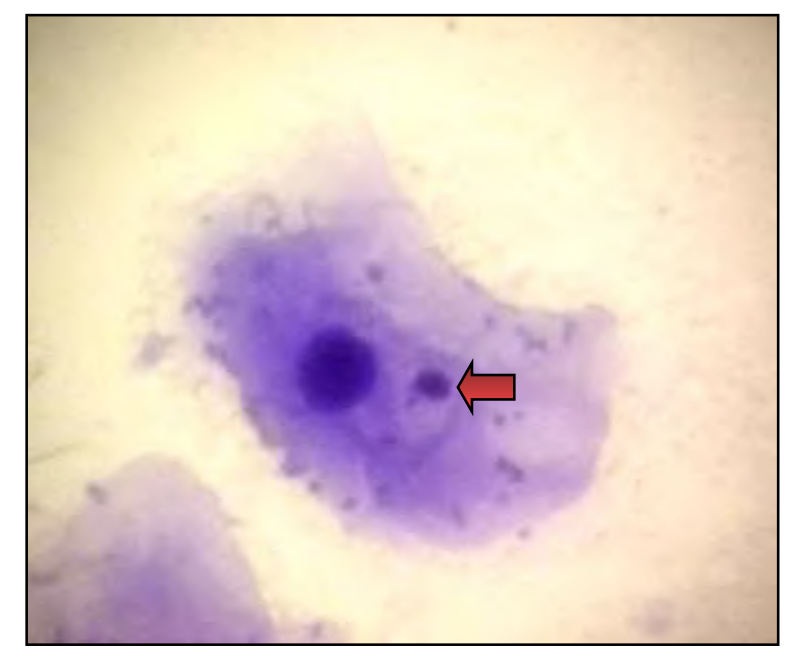

Fig.1: Photomicrograph of Giemsa-stained Micronucleus (arrow) in Human Buccal Cells (under High Power Objective). 
Table 2. The Incidence Rate of Genotoxicity among Tricycle Drivers of Pengue Ruyu, Tuguegarao City $(N=51)$.

\begin{tabular}{|c|c|c|c|c|}
\hline & \multirow{2}{*}{$\begin{array}{c}\text { Tricycle } \\
\text { drivers } \\
\end{array}$} & \multirow{2}{*}{$\begin{array}{c}\text { Percentage } \\
(\%)\end{array}$} & \multicolumn{2}{|c|}{$\begin{array}{c}\text { 95\% Confidence } \\
\text { Interval }\end{array}$} \\
\cline { 4 - 5 } & & & Lower & Upper \\
\hline $\begin{array}{c}\text { Positive } \\
\text { MN }\end{array}$ & 39 & 76.47 & 64.83 & 88.11 \\
\hline $\begin{array}{c}\text { Negative } \\
\text { MN }\end{array}$ & 12 & 23.53 & 11.89 & 35.17 \\
\hline
\end{tabular}

The incidence rate of genotoxicity among tricycle drivers of Pengue Ruyu is shown in Table 2. The table illustrates that $76.47 \%$ of the study participants tested positive for micronuclei. The high incidence of genotoxicity among the tricycle drivers could be attributed to several factors. One of these factors would be lower socioeconomic position (SEP). Samet et al (2000) indicated that groups with lower socioeconomic position (SEP) may receive higher exposure to air pollution. As such, people with low socioeconomic status may become more susceptible to the health effects of air pollution (Samet et al., 2000), and to cytogenetic damage brought about by automobile exhaust exposure.

Another factor that may have increased the incidence of genotoxicity among the tricycle drivers of Pengue Ruyu is the pollution level in Tuguegarao City. DENR EMB (2009) reported that Tuguegarao City exceeded the standards set by the WHO. In the study of Sree Devi et al (2009), a significant increase in the mean frequency of chromosomal aberrations was observed in traffic policemen exposed to polluted air. Also, they stated that vehicular exhaust, smoking, age, and duration of exposure had a cumulative effect with respect to the chromosomal aberrations in exposed traffic policemen. In the present study, majority of the tricycle drivers of Pengue Ruyu were middle-age men, had substantial exposure to automobile exhaust, and were cigarette smokers.

The length of exposure to urban air pollution could also be an attributable factor. The study conducted by Knudsen et al (1999) suggested that long-term exposure to urban air pollution (with traffic as the main contributor) induces chromosome damage in human somatic cells. In the present study, more than half of the population of the tricycle drivers of Pengue Ruyu had been exposed to urban air pollution for more than 10 years already.
Table 3. The incidence rate of genotoxicity among tricycle drivers of Pengue Ruyu who had low confidence of exposure and had substantial exposure to automobile exhaust.

\begin{tabular}{|c|c|c|c|c|c|c|}
\hline & \multicolumn{3}{|c|}{$\begin{array}{c}\text { Low Confidence of } \\
\text { Exposure }\end{array}$} & \multicolumn{3}{|c|}{ Substantial Exposure } \\
\hline & f & $\%$ & $95 \%$ C.I. & f & $\%$ & $\begin{array}{c}95 \% \\
\text { C.I. }\end{array}$ \\
\hline $\begin{array}{c}\text { Positive } \\
\text { MN }\end{array}$ & 4 & 40 & $\begin{array}{c}9.64 \text { to } \\
70.36\end{array}$ & 35 & 85.37 & $\begin{array}{c}74.55 \text { to } \\
96.18\end{array}$ \\
\hline $\begin{array}{c}\text { Negative } \\
\text { MN }\end{array}$ & 6 & 60 & $\begin{array}{c}29.64 \text { to } \\
90.36\end{array}$ & 6 & 14.63 & $\begin{array}{c}3.82 \text { to } \\
25.45\end{array}$ \\
\hline Total & 10 & 100 & -- & 41 & 100 & -- \\
\hline
\end{tabular}

Table 3 illustrates the incidence rate of genotoxicity among tricycle drivers of Pengue Ruyu who had low confidence of exposure and had substantial exposure to automobile exhaust. The incidence of genotoxicity in tricycle drivers who were substantially exposed to automobile exhaust [85.37\% (95\% CI: $74.55 \%-96.18 \%)$ ] is higher than that of the incidence in tricycle drivers with low confidence of exposure [ $40 \%$ (95\% CI: $9.64 \%-$ $70.36 \%)]$. This finding coincides with the results obtained by Anwar and Kamal (1988). The elevated cytogenetic damage may be attributed to exposure to pollutants from automobile exhaust (Anwar and Kamal, 1988).

\subsection{Risk Factors}

The present study also assessed the risk factors of genotoxicity among tricycle drivers of Pengue Ruyu, Tuguegarao City.

Table 4. Fisher's exact test statistic values

\begin{tabular}{|c|c|c|c|}
\hline $\begin{array}{c}\text { Independent } \\
\text { Variables }\end{array}$ & $\begin{array}{c}\text { Dependent } \\
\text { Variables }\end{array}$ & p-value & $\begin{array}{c}\text { Qualitative } \\
\text { Interpretation }\end{array}$ \\
\hline $\begin{array}{c}\text { Automobile } \\
\text { Exhaust } \\
\text { Exposure }\end{array}$ & $\begin{array}{c}\text { Presence } \\
\text { of MN }\end{array}$ & $0.0065^{*}$ & CORRELATED \\
Agse & $\begin{array}{c}\text { Presence } \\
\text { of MN }\end{array}$ & 0.9359 & NOR \\
\hline $\begin{array}{c}\text { Smoking } \\
\text { Habit }\end{array}$ & $\begin{array}{c}\text { Presence } \\
\text { of MN }\end{array}$ & 1.0000 & NORION \\
\hline $\begin{array}{c}\text { Alcohol } \\
\text { consumption }\end{array}$ & $\begin{array}{c}\text { Presence } \\
\text { of MN }\end{array}$ & 1.0000 & $\begin{array}{c}\text { NO } \\
\text { CORRELATION }\end{array}$ \\
\hline $\begin{array}{c}\text { History of } \\
\text { Respiratory } \\
\text { Disease }\end{array}$ & $\begin{array}{c}\text { Presence } \\
\text { of MN }\end{array}$ & 1.0000 & NORRELATION \\
\hline Vitamin & Presence & $0.0334^{*}$ & CORRELATED \\
\hline
\end{tabular}




\begin{tabular}{|c|c|c|c|}
\hline $\begin{array}{c}\text { intake } \\
\begin{array}{c}\text { Regularity of } \\
\text { driving } \\
\text { across Tanza }\end{array}\end{array}$ & $\begin{array}{c}\text { Presence } \\
\text { of MN }\end{array}$ & 0.7324 & $\begin{array}{c}\text { NO } \\
\text { CORRELATION }\end{array}$ \\
\hline $\begin{array}{c}\text { Duration of } \\
\text { work }\end{array}$ & $\begin{array}{c}\text { Presence } \\
\text { of MN }\end{array}$ & 0.2961 & $\begin{array}{c}\text { NO } \\
\text { CORRLLATION }\end{array}$ \\
\hline $\begin{array}{c}\text { Protective } \\
\text { Mask use }\end{array}$ & $\begin{array}{c}\text { Presence } \\
\text { of MN }\end{array}$ & 0.2320 & $\begin{array}{c}\text { NO } \\
\text { CORRELATION }\end{array}$ \\
\hline
\end{tabular}

**Significant association at $\mathrm{p}<0.05$.

Table 5. The Mean Frequency of Micronuclei (MN) among Study Groups.

\begin{tabular}{|c|c|c|c|}
\hline & $\mathbf{N}$ & $\begin{array}{c}\text { Number of } \\
\text { Micronucl } \\
\text { ei per } 1000 \\
\text { intact cells } \\
(\mathrm{MN} \pm \mathrm{SD})\end{array}$ & p-value \\
\hline $\begin{array}{l}\text { Low confidence of } \\
\text { Exposure } \\
\text { Substantial Exhaust } \\
\text { Exposure }\end{array}$ & $\begin{array}{l}10 \\
41\end{array}$ & $\begin{array}{l}1.20 \pm 1.81 \\
4.61 \pm 4.10\end{array}$ & $0.0138 *$ \\
\hline $\begin{array}{l}\text { With vitamins } \\
\text { Without vitamins }\end{array}$ & $\begin{array}{l}16 \\
35\end{array}$ & $\begin{array}{l}2.00 \pm 2.61 \\
4.60 \pm 4.06\end{array}$ & $0.0232 *$ \\
\hline $\begin{array}{c}\text { Protective mask users } \\
\text { Protective mask non-users }\end{array}$ & $\begin{array}{r}4 \\
47\end{array}$ & $\begin{array}{l}0.5 \pm 0.58 \\
4.02 \pm 3.89\end{array}$ & 0.0793 \\
\hline $\begin{array}{l}\text { Alcohol consumers } \\
\text { Alcohol abstinents }\end{array}$ & $\begin{array}{c}43 \\
8\end{array}$ & $\begin{array}{l}3.98 \pm 4.07 \\
2.5 \pm 2.20\end{array}$ & 0.3241 \\
\hline $\begin{array}{c}\text { Smokers } \\
\text { Non-Smokers }\end{array}$ & $\begin{array}{l}33 \\
18\end{array}$ & $\begin{array}{l}4.54 \pm 4.09 \\
3.33 \pm 3.12\end{array}$ & 0.2802 \\
\hline $\begin{array}{c}\text { With Respiratory disease } \\
\text { Without Respiratory } \\
\text { disease }\end{array}$ & $\begin{array}{l}9 \\
42\end{array}$ & $\begin{array}{l}3.89 \pm 4.62 \\
3.71 \pm 3.74\end{array}$ & 0.9005 \\
\hline $\begin{array}{c}\text { Always drive across } \\
\text { Tanza } \\
\text { Sometimes drive across } \\
\text { Tanza }\end{array}$ & 18 & $\begin{array}{l}4.39 \pm 3.91 \\
3.11 \pm 4.11\end{array}$ & 0.2778 \\
\hline
\end{tabular}

*Significant association at $\mathrm{p}<0.05$.

Table 4 reveals that among the categorical variables, only two variables, the automobile exhaust exposure and the vitamin intake, showed significant correlation with the presence of micronuclei.

Automobile exhaust exposure was found to be correlated with the presence of micronuclei. It was observed that the incidence of genotoxicity among tricycle drivers who were substantially exposed to automobile exhaust is lower compared to that of the incidence of genotoxicity among those with low confidence of exposure. Also, as shown in Table 5, the difference between the mean frequency of micronuclei in those with low confidence of exhaust exposure and in those with substantial exhaust exposure was established to be significantly different $(p<0.05)$. It was found out that the mean frequency of micronuclei in tricycle drivers who were substantially exposed to automobile exhaust is significantly higher than those with low confidence of exhaust exposure.

In this study, the tricycle drivers who were substantially exposed to the combustion products were those tricycle drivers who had been in the transport industry for more than 5 years, while those who had low confidence of exposure were those tricycle drivers who had been in the transport industry for 5 years and below. The above findings indicate that tricycle drivers substantially exposed to combustion products in automobile exhaust exhibit a significantly higher mean frequency of micronuclei compared to tricycle drivers who had low confidence of exposure. The higher mean frequency of micronuclei among the substantially exposed group may be an evidence of the clastogenic and/or aneugenic effects of the combustion products in automobile exhaust.

Another variable which was found to be statistically correlated with the presence of micronuclei is the intake of vitamins. It was observed that the incidence of genotoxicity among tricycle drivers who were taking vitamins is significantly lower than that of the incidence in tricycle drivers who had not taken any vitamins at all.

Table 5 shows also that the mean frequency of micronuclei in those who had taken vitamins and in those who had not taken any vitamins at all were significantly different $(p<0.05)$. It was found out that tricycle drivers who were taking vitamins tend to have a significantly lower mean frequency of micronuclei when compared to those who had not taken any vitamins at all. This implies further that those tricycle drivers who had not taken vitamins were more susceptible in developing cytogenetic damage due to automobile exhaust exposure.

In a study conducted by $\mathrm{Sia} \mathrm{Su}$ and Kayali (2008) regarding blood Vitamin $\mathrm{C}$ levels of the motorized tricycle drivers, it was found out through correlation analysis that majority $(79.6 \%)$ of drivers had low blood vitamin $\mathrm{C}$ levels. They reported that workplace and vitamin $\mathrm{C}$ supplementations $(p<0.5)$ were significantly related to the blood vitamin $\mathrm{C}$ levels of the motorized tricycle drivers. In the present study, the lower rates of vitamin supplementation and the workplace of the tricycle drivers 
could be factors that have increased the susceptibility of the tricycle drivers to cytogenetic damage.

Table 6. Relative Risk

\begin{tabular}{|c|c|c|c|c|}
\hline & & \multirow{2}{*}{ Risk } & \multicolumn{2}{|c|}{$\begin{array}{c}\text { 90\% Confidence } \\
\text { Interval }\end{array}$} \\
\cline { 4 - 5 } Exposure & Outcome & Ratio & $\begin{array}{c}\text { Lower } \\
\text { Limit }\end{array}$ & $\begin{array}{c}\text { Upper } \\
\text { Limit }\end{array}$ \\
\hline $\begin{array}{c}\text { Automobile } \\
\text { Exhaust } \\
\text { Exposure }\end{array}$ & $\begin{array}{c}\text { Presence } \\
\text { of MN }\end{array}$ & $2.13^{*}$ & 1.12 & 4.08 \\
\hline $\begin{array}{c}\text { Intake of } \\
\text { Vitamins }\end{array}$ & $\begin{array}{c}\text { Presence } \\
\text { of MN }\end{array}$ & $0.66^{* *}$ & 0.45 & 0.96 \\
\hline $\begin{array}{c}\text { Protective } \\
\text { Mask use }\end{array}$ & $\begin{array}{c}\text { Presence } \\
\text { of MN }\end{array}$ & 0.64 & 0.28 & 1.46 \\
\hline $\begin{array}{c}\text { Respiratory } \\
\text { Disease }\end{array}$ & $\begin{array}{c}\text { Presence } \\
\text { of MN }\end{array}$ & 1.02 & 0.74 & 1.42 \\
\hline Smoking & $\begin{array}{c}\text { Presence } \\
\text { Habit }\end{array}$ & 1.00 & 0.76 & 1.31 \\
\hline
\end{tabular}

*Risk factor

***Protective factor

In Table 6, the computed risk ratios of the different categorical variables were shown. Automobile exhaust exposure was found to be a risk factor, while intake of vitamins was found to be a protective factor.

Those tricycle drivers who were substantially exposed to automobile exhaust are 2.13 times more likely to develop cytogenetic damage than those tricycle drivers who had low confidence of exhaust exposure. Moreover, $90 \%$ of the time, when tricycle drivers were to be exposed at a higher exposure rate, the risk of developing cytogenetic damage may rise up to 4.08 times.

Meanwhile, those tricycle drivers who were taking vitamins reduce their risk of developing cytogenetic damage by $44 \%$. Also, when tricycle drivers are to take vitamins more frequently, the risk of developing cytogenetic damage may be reduced up to $55 \%$; however, when tricycle drivers are to take vitamins less frequently, the risk of developing cytogenetic damage may be reduced up to $4 \%$ only.

The usage of protective mask is supposed to be a protective factor since it has a risk ratio of 0.64. However, it is not statistically significant. Nonetheless, it is noteworthy as it may reduce the risk of developing cytogenetic damage by $72 \%$.

The results of this study significantly revealed that lesser exposure to automobile exhaust as well as more frequent intake of vitamins were associated with a reduced risk of ISSN: 2456-1878 developing cytogenetic damage among workers of the transport industry, especially among motorized tricycle drivers. Therefore, access to improved air sanitation as well as health education should be prioritized alongside preventive chemotherapy such as vitamins to achieve a durable reduction of the effects of automobile exhaust exposure among the motorized tricycle drivers.

\section{CONCLUSION}

In the light of the analysis of data and the findings of the study, the following conclusions were drawn:

1. The respondents were primarily middle-aged tricycle drivers whose route involves driving across Barangay Tanza. They were substantially exposed to automobile exhaust, majority of which do not use protective masks while driving. A significant proportion had no medical history of respiratory disease. Majority of the respondents were cigarette smokers and alcoholic beverage drinkers. Only a small proportion took vitamin supplements.

2. There is a high incidence of genotoxicity among the motorized tricycle drivers of Pengue-Ruyu, Tuguegarao City.

3. Among the variables, only automobile exhaust exposure and vitamin supplementation showed a significant correlation $(\mathrm{p}<0.05)$ in the development of cytogenetic damage. Automobile exhaust exposure was found to be a risk factor, while intake of vitamins as a protective factor.

4. There is no significant difference in the cytogenetic damage between those who use protective masks during driving and those who do not.

5. There is a significant difference in the cytogenetic damage between those who had a low-risk of exposure and high-risk of exposure to automobile exhaust.

\section{RECOMMENDATIONS}

To the Future Researchers, we recommend a larger sample size to achieve a lower margin of error. We would like also to recommend to the future researchers the use of other DNA-specific stains such as Feulgen stain so as to reduce the incidence of possible errors in the identification of micronucleus. Other procedural methods can also be used for the examination of the cytogenetic damage such as comet assay and Ames test.

\section{REFERENCES}

[1] World Health Organization (2008). Protecting Health From 
Climate Change. World Health Day 2008.

[2] DENR-EMB (2009). National Air Quality Status Report (2005-2007).

[3] World Health Organization (2002). The World Health Report 2002-Reducing Risks, Promoting Healthy Life.

[4] Domingo, L. (2013). Tricycle Wreak Worsening Pollution. The Manila Times. Retrieved from: http://www.Manilatimes.Net/Tricycles-Wreak-WorseningPollution/25529/

[5] DENR-EMB (2005). National Air Quality Status Report (2003-2004).

[6] Franco, S.S., A.C. Nardocci And W.M. Gunther, (2008). PAH Biomarkers For Human Health Risk Assessment: A Review Of The State-Of-The-Art. Cad. Saude Publica.24 Suppl 4:s569-80.

[7] Pant, H.H. \& M.V., Rao (2010). Evaluation Of In Vitro AntiGenotoxic Potential Of Melatonin Against Arsenic And Fluoride In Human Blood Cultures. Ecotoxicol. Environ. Safety.73(6):1333-7.

[8] Maluf, S.W., \& Erdtmann, B. (2000). Evaluation Of Occupational Risk In A Brazilian Hospital. Genet. Mol. Biol.23(2), 485-488.

[9] Fenech M, Chang WP, Kirsch-Volders M, Holland N, Bonassi S, Zeiger E (2003). HUMN Project: Detailed Description Of The Scoring Criteria For The Cytokines is block Micronucleus Assay Using Isolated Human Lymphocyte Cultures. Mutat Res.534(1-2):65-75

[10] Thomas, P., Holland, N., Bolognesi, C., Kirsch-Volders, M., Bonassi, S., Zeiger, E., Knasmueller, S., \& Fenech, M. (2009). Buccal micronucleus cytome assay. Nature Protocols, 4(6), 825-837.

[11] Tolbert, P. E., Shy, C. M. \& Allen, J. W. (1991). Micronuclei And Other Nuclear Anomalies In Buccal Smears: A Field Test In Snuff Users. American Journal Of Epidemiology.15;134(8):840-50.

[12] Samet JM, Zeger SL, Dominici F, Curriero F, Coursac I, Dockery DW, et al., (2000). The National Morbidity, Mortality, And Air Pollution Study. Part II: Morbidity And Mortality From Air Pollution In The United States. Res Rep Health Eff Inst.94(Pt 2):5-70

[13] Sree Devi, V., Durga Rao, V., Hara Gopal,V., Siva Prasad, B., Sandhya Devi, G., Jyothy, A., Reddy, P.P. \& Hema Prasad, M. (2009). Cytogenetic evaluation of traffic policemen occupationally exposed to vehicular exhaust. Indian J Med Res.130(5):520-5

[14] Knudsen, L.E., et al. (1999). Chromosomal Aberrations In Humans Induced By Urban Air Pollution: Influence Of DNA Repair And Polymorphisms Of Glutathiones-Transferase M1 And N-Acetyltransferase 2. Cancer Epidemiology, Biomarkers and Prevention.8(4);303-310.

[15] Anwar WA, and Kamal AA. Cytogenetic effects in a group of traffic policemen in Cairo. Mutat Res. 1988 Jul;208(3-4):22531.

[16] Sia Su GL, and Kayali S. (2008). Blood Vitamin C Levels Of Motorized Tricycle Drivers In Parañaque, Philippines. Ind Health.46(4):389-92. 